\title{
Coexistence of Calcification, Intraplaque Hemorrhage and Lipid Core within the Asymptomatic Atherosclerotic Carotid Plaque: The Rotterdam Study
}

\author{
Quirijn J.A. van den Bouwhuijsen ${ }^{a, b}$ Daniel Bos ${ }^{a, b} \quad$ M. Arfan Ikram ${ }^{a-c}$ \\ Albert Hofman $^{a} \quad$ Gabriel P. Krestin $^{b}$ Oscar H. Franco ${ }^{a}$ Aad van der Lugt ${ }^{b}$ \\ Meike W. Vernooija, b \\ Departments of a Epidemiology, ${ }^{\mathrm{b}}$ Radiology and ${ }^{\mathrm{c}}$ Neurology, Erasmus MC, Rotterdam, The Netherlands
}

\section{Key Words}

$\mathrm{CT} \cdot \mathrm{MRI} \cdot$ Atherosclerosis $\cdot$ Vulnerable plaque $\cdot$ Intraplaque hemorrhage $\cdot$ Lipid core $\cdot$ Calcifications

\begin{abstract}
Background: There is a growing amount of evidence suggesting that the composition of carotid atherosclerotic plaques may be of clinical relevance. Yet, little is known on the coexistence of potentially vulnerable and stabilizing components within asymptomatic plaques. Therefore, in this study we set out to investigate the coexistence of intraplaque calcification, hemorrhage and lipid core within the carotid artery using a multi-modality imaging approach. Methods: In 329 subjects from the population-based Rotterdam Study, all with ultrasound-confirmed carotid wall thickening, we performed a multi-detector CT and a high-resolution MRI of the carotid artery bifurcation at both sides. On the $C T$ examinations, we quantified the volume of intraplaque calcification, and using the MRI examinations we rated the presence of intraplaque hemorrhage and of lipid core. In total, we investigated 611 carotid arteries with plaques. With logistic regression models we investigated the relationship of calcification volume - as a potential stabilizing component - with the presence of potential vulnerable components (intraplaque hemorrhage and lipid core) within each
\end{abstract}

(c) 2015 S. Karger AG, Basel

1015-9770/15/0396-0319\$39.50/0 carotid plaque. We adjusted all analyses for age, sex and maximal plaque thickness. Next, we stratified on degree of stenosis ( $\leq$ or $>30 \%$ ) to evaluate effect modification by atherosclerotic burden. Results: We found that a larger calcification volume was associated with a higher prevalence of intraplaque hemorrhage, and a lower prevalence of lipid core (fully-adjusted odds ratio (OR) per standard deviation (SD) increase in calcification volume: 2.04 (95\% confidence intervals (Cl): $1.49 ; 2.78)$ and $0.72(95 \% \mathrm{Cl}: 0.58 ; 0.90)$, respectively). Stratification on the degree of stenosis showed no difference in the association between calcification volume and hemorrhage over strata, while the relationship between a larger calcification volume and a lower prevalence of lipid seemed more pronounced in persons with a high degree of stenosis. Conclusions: In this population-based setting, we found that there is a complex relationship between calcification, intraplaque hemorrhage and lipid core within the carotid atherosclerotic plaque. Plaques with a higher load of calcification contain more often hemorrhagic components, but less often lipid core. Our results suggest that both in small and large plaques, intraplaque calcification may not be a stabilizing factor per se. These findings create an urge for

Quirijn J.A.van den Bouwhuijsen and Daniel Bos contributed equally to this work.

\section{KARGER 125}

E-Mail karger@karger.com www.karger.com/ced
Meike W. Vernooij

Department of Radiology, Erasmus MC

's-Gravendijkwal 230, PO Box 2040

NL-3000CA Rotterdam (The Netherlands)

E-Mail m.vernooij@erasmusmc.nl 
conducting prospective studies investigating the interrelation of these different plaque components with regard to future cerebrovascular events.

ㄷ) 2015 S. Karger AG, Basel

\section{Introduction}

Atherosclerosis is a systemic vascular disease, which is highly frequent in middle-aged and elderly persons $[1,2]$. Atherosclerosis is characterized by the thickening of the arterial vessel wall, which can be due to accumulation of lipid material, calcification, fibrous elements and/or intraplaque hemorrhage.

Atherosclerosis in the carotid artery is well established as a causal factor in clinical stroke [3]. Initial studies on carotid atherosclerosis primarily focused on atherosclerotic burden, as assessed by carotid intima-media thickness, degree of stenosis, or plaque size $[4,5]$. More recent evidence shows that the composition of the atherosclerotic plaque may also provide essential information for cardiovascular disease prevention and management [68]. Clinical studies have convincingly shown that certain plaque components, that is, intraplaque hemorrhage and lipid core, are associated with plaque instability and plaque rupture, and as such with an increased risk of stroke [7-9].

Contrary to these markers of plaque instability, there is emerging evidence that other plaque components, in particular calcification, may actually have a stabilizing effect on the plaque, which might lead to a decreased risk of stroke [10-12].

Whereas clinical studies primarily represent symptomatic atherosclerosis, it is increasingly recognized that studying atherosclerosis in preclinical, asymptomatic individuals (e.g. in a population-based setting) can provide important insights into etiology and prognosis of atherosclerosis. Though risk factors for specific plaque components have been described [13], it remains unknown how different plaque components associate with each other within these asymptomatic plaques. Advances in noninvasive imaging techniques, specifically computed tomography (CT) and magnetic resonance imaging (MRI), have led to the possibility to noninvasively study atherosclerosis in large samples from the general population [4]. Using these imaging techniques, important information on the prevalence of different plaque components in asymptomatic persons has been obtained during the last decades [14-16]. In particular, it was found that intraplaque hemorrhage and lipid core are also highly frequent plaque components in the general population [13].

Thus far, studies have used a single imaging modality (either CT or MRI) to investigate atherosclerotic plaques. This precludes the concomitant study of intraplaque hemorrhage and lipid core, which are best seen on MRI, and calcification, which is optimally detected with CT [4].

Therefore, in this study, we set out to investigate the coexistence of various atherosclerotic plaque components within the carotid artery using a multi-modality imaging approach in a sample of 329 community-dwelling persons from the Rotterdam Study. We hypothesized that a high load of calcification would be related to the less frequent occurrence of vulnerable components (i.e. hemorrhage and lipid) within the same plaque.

\section{Methods}

\section{Study Population}

This study is embedded in the Rotterdam Study [17], a prospective, population-based cohort study among persons aged 55 years or older. The original cohort consisted of 7,983 participants and was extended in 2000-2001 with 3,011 persons. At study entry and every 3-4 years, all participants are reexamined in a dedicated research center. From 2003 until 2006, all participants that completed a visit at the research center in this period were invited to undergo CT of the extracranial internal carotid arteries [15]. In total, 2,524 participants were scanned. From October 2007 onwards, carotid MRI was incorporated in the study in all persons with carotid wall thickening in the left, right or both carotid arteries on ultrasound [13]. Invitation for carotid MRI was independent from previous participation in the carotid CT study. Until September 2010, 829 persons from the original and extended cohort underwent carotid MRI, of whom 349 had undergone CT in the period 2003-2006. This study focuses on these participants who had both a complete CT- and MRI-examination until September $2010(n=349)$. Moreover, we excluded all participants with a history of stroke $(n=20)$ to restrict our analyses to a completely asymptomatic population, leaving a study population of 329 persons. The mean time interval between CT and MRI was $4.6 \pm 1.1$ years, with the carotid CT scan preceding the MRI in all subjects. The Rotterdam Study has been approved by the medical ethics committee according to the Population Study Act Rotterdam Study, executed by the Ministry of Health, Welfare and Sports of the Netherlands. A written informed consent was obtained from all participants.

\section{CT Acquisition and Processing}

CT imaging was performed using a 16 -slice $(n=122)$ or 64 -slice $(\mathrm{n}=207)$ multidetector computed tomography (MDCT) scanner (Somatom Sensation 16 or 64, Siemens, Forcheim, Germany). No contrast material was administered. To visualize the calcification in the extracranial carotid arteries, we used a scan that reached from the aortic arch to the intracranial vasculature $(1 \mathrm{~cm}$ above the 
sella turcica). Detailed information regarding imaging parameters of the scan is described elsewhere [15].

Calcification in the extracranial carotid artery was measured bilaterally within 3 centimeters proximal and distal of the bifurcation, and quantified with dedicated commercially available software (syngo CalciumScoring, Siemens, Germany) [15]. Calcification volumes in both left and right carotid arteries were expressed as cubic millimeters $\left(\mathrm{mm}^{3}\right)$.

\section{MRI Acquisition and Processing}

Imaging of the carotid arteries was performed on a 1.5-T scanner (GE Healthcare, Milwaukee, Wis., USA) with a bilateral phased-array surface coil (Machnet, Eelde, The Netherlands). We planned the high-resolution MRI sequences so that the carotid plaques were imaged completely on both sides, using a previously described standardized protocol [13]. First, both carotid bifurcations were identified by means of 2D Time of Flight MR-Angiography. Thereafter, high-resolution MRI sequences were planned to image the carotid bifurcations on both sides: a PDw Fast Spin Echo (FSE) Black-blood (BB) sequence; a PDw-FSE-BB with an increased in-plane resolution; a PDw-Echo Planar Imaging (EPI) sequence; a T2w-EPI sequence; a 3D-T1w-Gradient Echo (GRE) sequence; and, finally, a 3D Phased-Contrast MRAngiography.

Carotid plaques were analyzed by a single observer, blinded to CT results, with more than three years experience in rating MRI carotid, as previously described [13]. Analysis involved the examination of both carotid arteries. First, the presence of atherosclerotic plaque in each carotid artery was assessed. Next, carotid plaque thickness was quantified by measuring maximum carotid wall thickness in the PDw-FSE images and by calculation of luminal stenosis using the NASCET criteria [13]. In carotid arteries with maximum wall thickness of $\geq 2.0 \mathrm{~mm}$ on MRI ( $\mathrm{n}=611$ carotids in 329 participants), the presence or absence of intraplaque hemorrhage and lipid core was assessed using criteria as described elsewhere [13].

\section{Statistical Analysis}

Since calcification volume had a highly skewed, non-normal distribution, we used natural log-transformed values and added $1.0 \mathrm{~mm}^{3}$ to the non-transformed values in order to deal with calcium scores of zero $\left(\ln \left(\right.\right.$ calcification $\left.\left.+1.0 \mathrm{~mm}^{3}\right)\right)$.

We used Generalized Estimation Equation (GEE) analyses to investigate the relationship of CT-assessed calcification volume in each extracranial internal carotid artery with the degree of stenosis (dichotomized into $0-30$ and $>30 \%$ ), the presence of intraplaque hemorrhage and lipid core on MRI. These analyses were modelled with an unstructured working correlation matrix that included two levels per participant, namely, the left and right carotid arteries, in order to adjust for the correlation between plaques in the two carotid arteries of the same participant. In model 1, we adjusted for age and sex. In model 2, we additionally adjusted for maximum carotid wall thickness as proxy of plaque size, measured on MRI. Next, we stratified on the degree of carotid stenosis (0-30 vs. $>30 \%$ ) and repeated the aforementioned analyses, to assess whether the relationships between calcification volume and the other plaque components were modified by severity of atherosclerosis. We used the $30 \%$ cut-off for the degree of stenosis because our study population is a community dwelling population, which means that the degree of stenosis is relatively lower than in a hos-

Coexistence of Plaque Components in the

Carotid Atherosclerotic Plaque
Table 1. Population characteristics

$\begin{array}{lc}\text { Sample size, } \mathrm{n} & 329 \\ \text { Carotids, } \mathrm{n} & 611 \\ \text { Women } & 43.0 \\ \text { Age* }^{*} \text { years } & 70.0(6.2) \\ {\text { Body mass index, } \mathrm{kg} / \mathrm{m}^{2}} & 27.3(3.4) \\ \text { Systolic blood pressure, mm Hg } & 147.5(20.1) \\ \text { Diastolic blood pressure, mm Hg } & 79.6(11.5) \\ \text { Past or current smokers } & 72.5 \\ \text { Diabetes } & 12.8 \\ \text { Total cholesterol, mmol/l } & 5.5(1.0) \\ \text { Calcification volume }{ }^{\dagger}, \mathrm{mm}^{3} & 59.0(16.6-144.1) \\ \text { Presence of intraplaque hemorrhage } & 26.5 \\ \text { Presence of lipid core } & 23.7 \\ \text { Carotid stenosis }>30 \% & 13.1 \\ \text { Maximum carotid wall thickness, mm } & 3.3(1.0)\end{array}$

Values are means (standard deviation) for continuous variables and percentages for dichotomous variables.

* Age at time of CT examination.

$\dagger$ Median with interquartile range.

pital-based or high-risk population [18]. Additionally, we adjusted model 1 and 2 for inter-scan interval. IBM SPSS Statistics version 20 (International Business Machines Corporation, Armonk, New York, N.Y., USA) was used for statistical analyses.

\section{Results}

The characteristics of the study population are described in table 1 . The mean age at the time of the CTexamination was $70.0 \pm 6.2$ years and $43.0 \%$ were women.

As expected, larger calcification volume was associated with the presence of carotid stenosis (odds ratio (OR) per standard deviation (SD) increase in calcification volume: 1.57 (95\% CI: 1.10; 2.17)). Furthermore, a higher calcification load was related to the presence of intraplaque hemorrhage (OR per SD increase in calcification volume: 2.65 (95\% CI: 1.94; 3.64)), but not to lipid (table 2, model 1). An additional adjustment for maximum plaque thickness rendered the association with carotid stenosis insignificant, but the association with intraplaque hemorrhage remained (OR per SD increase in calcification volume: 2.04 (95\% CI: $1.49 ; 2.78)$ ). Moreover, in this model, larger calcification volume also associated with a lower prevalence of lipid core in the plaque (OR per SD increase in calcification volume: 0.72 (95\% CI: $0.58 ; 0.90)$ ) (table 2 , model 2). After stratification for the degree of stenosis, we found that larger calcification volume was significantly associated with the presence of intraplaque hemorrhage in both 
Table 2. Association between calcification volume (CT) and other plaque characteristics (MRI)

\begin{tabular}{lllll}
\hline Calcification volume & & Stenosis* & Lipid core & Intraplaque hemorrhage \\
\hline Per SD & Model 1 & $\mathbf{1 . 5 7}(\mathbf{1 . 1 0} ; \mathbf{2 . 1 7})$ & $0.93(0.77 ; 1.12)$ & $\mathbf{2 . 6 5}(\mathbf{1 . 9 4} ; \mathbf{3 . 6 4 )}$ \\
& Model 2 & $0.98(0.70 ; 1.43)$ & $\mathbf{0 . 7 2}(\mathbf{0 . 5 8} \mathbf{0 . 9 0 )}$ & $\mathbf{2 . 0 4}(\mathbf{1 . 4 9 ; 2 . 7 8 )}$ \\
\hline
\end{tabular}

Values represent odds ratios with $95 \%$ confidence intervals per standard deviation increase in calcification volume. Bold numbers indicate statistically significant association $(\mathrm{p}<0.05)$.

* Stenosis is defined as $>30 \%$.

Model 1: adjusted for age and sex.

Model 2: adjusted for age, sex and maximum plaque thickness.

Table 3. Association between calcification volume (CT) and other plaque characteristics (MRI) stratified by degree of stenosis

\begin{tabular}{|c|c|c|c|c|c|}
\hline \multirow{2}{*}{$\begin{array}{l}\text { Calcification } \\
\text { volume }\end{array}$} & & \multicolumn{2}{|l|}{ Stenosis $\leq 30 \%$} & \multicolumn{2}{|l|}{ Stenosis $>30 \%$} \\
\hline & & lipid core & intraplaque hemorrhage & lipid core & intraplaque hemorrhage \\
\hline Per SD & Model 2 & $0.76(0.59 ; 0.97)$ & $2.17(1.48 ; 3.17)$ & $0.51(0.30 ; 0.86)$ & $2.12(1.25 ; 3.62)$ \\
\hline
\end{tabular}

Values represent odds ratios with 95\% confidence intervals per standard deviation increase in calcification volume. Bold numbers indicate statistically significant association $(\mathrm{p}<0.05)$. $\mathrm{p}$ for interaction was 0.07 for lipid core, and 0.34 for intraplaque hemorrhage.

Model 1: adjusted for age and sex.

Model 2: adjusted for age, sex and maximum plaque thickness.

strata (OR per SD increase in calcification volume: 2.00 (95\% CI: $1.24 ; 3.22)$ for $\leq 30 \%$ stenosis and 2.76 (95\% CI: 1.88 ; 4.06 ) for $>30 \%$ stenosis) (table 3 , model 1 ). A stenosis of $30 \%$ is in clinical practice not considered significant, and that for treatment decisions dichotomization is usually made at higher degrees of stenosis.

After the additional adjustment for the maximum plaque thickness is done, this association did not change. In persons with a high degree of stenosis $(>30 \%)$, larger calcification volume was additionally associated with a lower prevalence of lipid core in the plaque (OR per SD increase in calcification volume: 0.55 (95\% CI: 0.33; 0.92)) (table 3, model 1). Additional adjustment for maximum plaque thickness rendered the association between larger calcification and a lower prevalence of lipid core in persons with a low degree of stenosis (0-30\%) to be also statistically significant (OR per SD increase in calcification volume: 0.76 (95\% CI: 0.59; 0.97)) (table 3, model 2). The $\mathrm{p}$ value for interaction was 0.07 for lipid core, and 0.34 for intraplaque hemorrhage. Additional adjustments for inter-scan interval did not alter our results (online suppl. tables 1 and 2; for all online suppl. material, see www. karger.com/doi/10.1159/000381138).

\section{Discussion}

In a sample of 329 persons with asymptomatic carotid wall thickening from the general population, we found that a larger calcification volume was associated with a higher prevalence of intraplaque hemorrhage, but conversely also with a lower prevalence of lipid core. These associations remained after the adjustment for markers of atherosclerotic burden, that is, the degree of stenosis and maximum plaque thickness.

The major strengths of our study include the population-based setting and the use of multiple imaging modalities within study subjects. We used both CT and MRI to assess the different plaque components in each carotid artery. MRI is very well able to accurately visualize soft plaque components, that is, intraplaque hemorrhage and lipid. On the other hand, CT is superior in detecting and quantifying calcification. To our knowledge, the technique of combining the strengths of multiple imaging modalities for the study of carotid atherosclerotic plaque in a population-based setting has not been applied before. Furthermore, we assessed plaque components per carotid artery and analyzed these on the level of the carotid artery 
instead of on a person-level, enabling to study the coexistence of components within the plaque.

Several potential limitations should be considered. First, we did not use contrast-enhanced MRI and thus potentially were less sensitive in our detection of lipid core [19]. However, the non-contrast-enhanced sequences we used were repeatedly shown to have high accuracy in validation studies [20-22]. Second, we could not image other characteristics of plaque vulnerability, for example, fibrous cap inflammation or instability, thereby lacking the possibility to evaluate the association between calcification load and these signs of vulnerability. Furthermore, we assessed solely the presence or absence of hemorrhage and lipid core and not the volume of these components. Finally, the time interval between the CT- and MRI-examinations was relatively long (4.6 years on average), and we acknowledge that there may have been slight changes in plaque composition, especially the soft plaque components, during this time interval [23]. Yet, in all participants the CT examination preceded the MRI examination. Under these circumstances, it is important to consider that calcification is a plaque component that generally remains present and shows only very slow progression over time $[24,25]$. Therefore, it seems unlikely that the calcification load at the time of MRI would be very different from the load at the time of the CT examination. This suggests that the time interval between the assessments of the different plaque components in our study would not have any major influence, which is supported by the fact that adjustment for inter-scan interval did not change the results.

We found a larger carotid calcification volume at the level of the bifurcation related to presence of intraplaque hemorrhage. This is an interesting finding because intraplaque hemorrhage is considered an important, if not, the most important vulnerable plaque component [26]. On the other hand, plaque calcification is often considered a stabilizing plaque characteristic [8]. The association we found did not seem to be driven simply by plaque size or atherosclerotic burden, as it did not alter after an adjustment was made for wall thickness and was even more pronounced in persons with a low degree of carotid stenosis. This raises the question whether plaque calcification is really a plaque stabilizer, or what the net effect is of both stabilizing and vulnerable components within a single plaque [10].

Contrary to intraplaque hemorrhage, we found that larger calcification volumes were associated with a lower prevalence of lipid core, which was more pronounced at a higher degree of stenosis $(>30 \%)$. This may indeed suggest that the amount of calcification within a plaque leaves

Coexistence of Plaque Components in the Carotid Atherosclerotic Plaque less room for lipid, which may be suggestive for stabilization of the plaque to some extent; nevertheless, the exact details of how this process unravels remain unclear. Furthermore, we should consider that at higher degrees of stenosis, selective non-participation may have occurred for persons with vulnerable plaque, which may also have influenced this association.

Our findings thus suggested that a larger amount of atherosclerotic calcification in the carotid plaque does not automatically indicate that the plaque was more stable. More supporting evidence for this came from studies in which the location (superficial, deep) and type of calcification (patchy, coalesced) were suggested to be important with regard to the plaque instability [27, 28]. Especially, those plaques with multiple patchy locations of calcification might be at a higher risk of rupture due to the mechanical instability caused at the interface of 'hard' calcification with 'soft', noncalcified plaque [27]. Unfortunately, we could not investigate this because contrast-enhanced CT would be necessary to detect a few of these characteristics. Our findings underline that more research into the characteristics of plaque calcification, for example, morphology and location, and into the relationship with vulnerable plaque components and future cardiovascular events (in a prospective design) is necessary.

In conclusion, we found that there is a complex relationship between calcification, intraplaque hemorrhage and lipid core within the carotid atherosclerotic plaque. Plaques with a higher load of calcification contain more often hemorrhagic components, but less often lipid core. These findings highlight the need for prospective studies investigating the interrelation of these different plaque components with regard to future cerebrovascular events.

\section{Sources of Funding}

The Rotterdam Study is funded by Erasmus Medical Center and Erasmus University Rotterdam, the Netherlands; the Research Institute for Diseases in the Elderly; the Ministry of Education, Culture and Science; the Ministry for Health, Welfare and Sports; the European Commission (DG XII); and the Municipality of Rotterdam. This study was supported by grants from the Netherlands Heart Foundation (2006B206, 2009B044), the Netherlands Organization for Scientific Research (NWO)/the Netherlands Organization for Health Research and Development ZonMw) (Vici grant 918.76.619), and the Netherlands Consortium for Healthy Ageing.

\section{Disclosure Statement}

None. 


\section{References}

1 Libby P, Ridker PM, Hansson GK: Progress and challenges in translating the biology of atherosclerosis. Nature 2011;473:317-325.

12 Lusis AJ: Atherosclerosis. Nature 2000;407: 233-241.

-3 Donnan GA, Fisher M, Macleod M, Davis SM: Stroke. Lancet 2008;371:1612-1623.

$\checkmark 4$ Owen DR, Lindsay AC, Choudhury RP, Fayad ZA: Imaging of atherosclerosis. Annu Rev Med 2011;62:25-40.

5 Polak JF, Pencina MJ, Pencina KM, O’Donnell CJ, Wolf PA, D’Agostino RB Sr: Carotid-wall intima-media thickness and cardiovascular events. N Engl J Med 2011;365:213-221.

-6 Naghavi M, Falk E, Hecht HS, Jamieson MJ, Kaul S, Berman D, Fayad Z, Budoff MJ, Rumberger J, Naqvi TZ, Shaw LJ, Faergeman O, Cohn J, Bahr R, Koenig W, Demirovic J, Arking D, Herrera VL, Badimon J, Goldstein JA, Rudy Y, Airaksinen J, Schwartz RS, Riley WA, Mendes RA, Douglas P, Shah PK: From vulnerable plaque to vulnerable patient - part III: executive summary of the screening for heart attack prevention and education (SHAPE) task force report. Am J Cardiol 2006;98:2H$15 \mathrm{H}$.

7 Naghavi M, Libby P, Falk E, Casscells SW, Litovsky S, Rumberger J, Badimon JJ, Stefanadis C, Moreno P, Pasterkamp G, Fayad Z, Stone PH, Waxman S, Raggi P, Madjid M, Zarrabi A, Burke A, Yuan C, Fitzgerald PJ, Siscovick DS, de Korte CL, Aikawa M, Airaksinen KE, Assmann G, Becker CR, Chesebro JH, Farb A, Galis ZS, Jackson C, Jang IK, Koenig W, Lodder RA, March K, Demirovic J, Navab M, Priori SG, Rekhter MD, Bahr R, Grundy SM, Mehran R, Colombo A, Boerwinkle E, Ballantyne C, Insull W Jr, Schwartz RS, Vogel R, Serruys PW, Hansson GK, Faxon DP, Kaul S, Drexler H, Greenland P, Muller JE, Virmani R, Ridker PM, Zipes DP, Shah PK, Willerson JT: From vulnerable plaque to vulnerable patient: a call for new definitions and risk assessment strategies: part II. Circulation 2003;108:1772-1778.

8 Naghavi M, Libby P, Falk E, Casscells SW, Litovsky S, Rumberger J, Badimon JJ, Stefanadis C, Moreno P, Pasterkamp G, Fayad Z, Stone PH, Waxman S, Raggi P, Madjid M, Zarrabi A, Burke A, Yuan C, Fitzgerald PJ, Siscovick DS, de Korte CL, Aikawa M, Juhani Airaksinen KE, Assmann G, Becker CR, Chesebro JH, Farb A, Galis ZS, Jackson C, Jang IK, Koenig W, Lodder RA, March K, Demirovic J, Navab M, Priori SG, Rekhter MD, Bahr R, Grundy SM, Mehran R, Colombo A, Boerwinkle E, Ballantyne C, Insull W Jr, Schwartz RS, Vogel R, Serruys PW, Hansson GK, Faxon
DP, Kaul S, Drexler H, Greenland P, Muller JE, Virmani R, Ridker PM, Zipes DP, Shah PK, Willerson JT: From vulnerable plaque to vulnerable patient: a call for new definitions and risk assessment strategies: part I. Circulation 2003;108:1664-1672.

-9 Alsheikh-Ali AA, Kitsios GD, Balk EM, Lau J, Ip S: The vulnerable atherosclerotic plaque: scope of the literature. Ann Intern Med 2010; 153:387-395.

10 Nandalur KR, Baskurt E, Hagspiel KD, Phillips CD, Kramer CM: Calcified carotid atherosclerotic plaque is associated less with ischemic symptoms than is noncalcified plaque on MDCT. AJR Am J Roentgenol 2005; 184:295-298.

11 Ulzheimer S, Kalender WA: Assessment of calcium scoring performance in cardiac computed tomography. Eur Radiol 2003;13:484497.

12 Kwee RM: Systematic review on the association between calcification in carotid plaques and clinical ischemic symptoms. J Vasc Surg 2010;51:1015-1025.

13 van den Bouwhuijsen QJ, Vernooij MW, Hofman A, Krestin GP, van der Lugt A, Witteman JC: Determinants of magnetic resonance imaging detected carotid plaque components: the Rotterdam study. Eur Heart J 2012;33: 221-229.

14 Allison MA, Criqui MH, Wright CM: Patterns and risk factors for systemic calcified atherosclerosis. Arterioscler Thromb Vasc Biol 2004;24:331-336.

15 Odink AE, van der Lugt A, Hofman A, Hunink MG, Breteler MM, Krestin GP, Witteman JC: Association between calcification in the coronary arteries, aortic arch and carotid arteries: the Rotterdam study. Atherosclerosis 2007;193:408-413.

16 Wolff T, Guirguis-Blake J, Miller T, Gillespie $M$, Harris R: Screening for carotid artery stenosis: an update of the evidence for the U.S. preventive services task force. Ann Intern Med 2007;147:860-870.

17 Hofman A, van Duijn CM, Franco OH, Ikram MA, Janssen HL, Klaver CC, Kuipers EJ, Nijsten TE, Stricker BH, Tiemeier H, Uitterlinden AG, Vernooij MW, Witteman JC: The Rotterdam Study: 2012 objectives and design update. Eur J Epidemiol 2011;26:657686.

-18 Bos D, Portegies ML, van der Lugt A, Bos MJ, Koudstaal PJ, Hofman A, Krestin GP, Franco $\mathrm{OH}$, Vernooij MW, Ikram MA: Intracranial carotid artery atherosclerosis and the risk of stroke in whites: the Rotterdam study. JAMA Neurol 2014;71:405-411.
19 Cai J, Hatsukami TS, Ferguson MS, Kerwin WS, Saam T, Chu B, Takaya N, Polissar NL, Yuan C: In vivo quantitative measurement of intact fibrous cap and lipid-rich necrotic core size in atherosclerotic carotid plaque: comparison of high-resolution, contrast-enhanced magnetic resonance imaging and histology. Circulation 2005;112:3437-3444.

20 Cappendijk VC, Cleutjens KB, Kessels AG Heeneman S, Schurink GW, Welten RJ, Mess WH, Daemen MJ, van Engelshoven JM, Kooi ME: Assessment of human atherosclerotic carotid plaque components with multisequence MR imaging: initial experience. Radiology 2005;234:487-492.

-21 Yuan C, Mitsumori LM, Beach KW, Maravilla KR: Carotid atherosclerotic plaque: noninvasive $M R$ characterization and identification of vulnerable lesions. Radiology 2001;221: 285-299.

-22 Saam T, Ferguson MS, Yarnykh VL, Takaya N, Xu D, Polissar NL, Hatsukami TS, Yuan C: Quantitative evaluation of carotid plaque composition by in vivo MRI. Arterioscler Thromb Vasc Biol 2005;25:234-239.

23 Sun J, Underhill HR, Hippe DS, Xue Y, Yuan C, Hatsukami TS: Sustained acceleration in carotid atherosclerotic plaque progression with intraplaque hemorrhage: a long-term time course study. JACC Cardiovasc Imaging 2012;5:798-804.

24 van Gils MJ, Bodde MC, Cremers LG, Dippel DW, van der Lugt A: Determinants of calcification growth in atherosclerotic carotid arteries; a serial multi-detector CT angiography study. Atherosclerosis 2013;227:95-99.

25 van Gils MJ, Vukadinovic D, van Dijk AC, Dippel DW, Niessen WJ, van der Lugt A: Carotid atherosclerotic plaque progression and change in plaque composition over time: a 5-year follow-up study using serial CT angiography. AJNR Am J Neuroradiol 2012;33: 1267-1273

26 Hellings WE, Peeters W, Moll FL, Piers SR, van Setten J, Van der Spek PJ, de Vries JP, Seldenrijk KA, De Bruin PC, Vink A, Velema E, de Kleijn DP, Pasterkamp G: Composition of carotid atherosclerotic plaque is associated with cardiovascular outcome: a prognostic study. Circulation 2010;121:1941-1950.

27 Abedin M, Tintut Y, Demer LL: Vascular calcification: mechanisms and clinical ramifications. Arterioscler Thromb Vasc Biol 2004;24: 1161-1170.

28 Finn AV, Nakano M, Narula J, Kolodgie FD, Virmani R: Concept of vulnerable/unstable plaque. Arterioscler Thromb Vasc Biol 2010; 30:1282-1292. 